\title{
Changes in biomarkers of nutrient metabolism, inflammation, and oxidative stress in dairy cows during the transition into the early dry period
}

\author{
A. K. Putman, J. L. Brown, J. C. Gandy, L. Wisnieski, and L. M. Sordillo ${ }^{1}$ \\ Department of Large Animal Clinical Sciences, College of Veterinary Medicine, Michigan State University, East Lansing 48824
}

\begin{abstract}
Metabolic stress occurs in dairy cows when physiologic homeostasis is disrupted as a consequence of aberrant nutrient metabolism, chronic inflammation, and oxidative stress. Early-lactation cows that suffer from metabolic stress are susceptible to health disorders that cause significant production losses. However, there is little information regarding the occurrence and effect of metabolic stress during involution. Therefore, the purpose of this study was to investigate well-known biomarkers associated with metabolic stress in earlylactation cows at various time points during the early dry period when dairy cows also are subjected to dramatic changes in physiologic homeostasis. Our group conducted a descriptive study by collecting serum and whole-blood samples from the coccygeal vein of 29 healthy dairy cows at a commercial dairy herd. Sampling points included $\mathrm{d}-6,0,+1,+2,+6$, and +12 relative to dry-off date. Samples were used to quantify biomarkers related to nutrient metabolism, oxidative stress, and inflammation that included calcium, nonesterified fatty acids, $\beta$-hydroxybutyrate, albumin, haptoglobin, cortisol, reactive oxygen and nitrogen species, antioxidant potential, oxidant status index, and isoprostanes. Additionally, whole-blood leukocyte differentials for total leukocyte, neutrophils, lymphocytes, eosinophils, and monocytes were analyzed. Within altered nutrient metabolism biomarkers, calcium and nonesterified fatty acid concentrations changed most from $\mathrm{d} 0$ to $\mathrm{d}$ +2 during the sampling period. Indicators of oxidant status, such as reactive oxygen and nitrogen species, antioxidant potential, and oxidant status index, generally increased throughout the sampling period except at $\mathrm{d}+2$, suggesting altered redox status throughout early involution. In contrast, isoprostane concentrations fluctuated throughout the study, demonstrating that indicators of oxidative damage occurred more sporadically during the sampling period. Therefore,
\end{abstract}

Received February 14, 2018.

Accepted June 4, 2018.

${ }^{1}$ Corresponding author: sordillo@msu.edu many of the biomarkers associated with early-lactation metabolic stress also changed during the transition from late lactation to the early dry period, but not to the same magnitude and duration previously reported in periparturient cows. Future studies should be directed toward assessing whether the magnitude and duration of biomarker expression can affect the health and wellbeing of cows during the early dry period.

Key words: dry cow, metabolic stress, involution, inflammation

\section{INTRODUCTION}

The dry period is the critical time between lactations in which a cow's mammary gland remodels and regenerates in preparation for the ensuing lactation. During this time, high-producing dairy cows are subject to stressors such as an abrupt cessation in milking, mammary gland discomfort, and physiological imbalances such as altered energy, immune, and hormonal states (Zobel et al., 2015). For instance, intramammary pressure increases when the udder becomes engorged with milk after abrupt milking cessation, leading to discomfort. Acute involution also follows abrupt milking cessation and elicits an inflammatory response, further causing cattle distress (Zobel et al., 2015). Early involution is a critical transition for dairy cows; however, most retrospective and prospective studies have focused instead on health risk factors associated with the periparturient period such as metabolic stress (Sordillo and Mavangira, 2014).

Metabolic stress is a cluster of risk factors in periparturient cows that leads to an increased susceptibility to certain health disorders, such as metritis and mastitis (Sordillo and Mavangira, 2014). Metabolic stress of periparturient cows is analogous to metabolic syndrome in humans and results from a combination of aberrant nutrient metabolism leading to dyslipidemia, chronic inflammation, and oxidative stress (Sordillo et al., 2009; Sordillo and Mavangira, 2014; Mbata et al., 2017). For instance, early-lactation cows that cannot meet energy demands through DMI experience aberrant nutrient metabolism, indicated by biomarkers 
of fat mobilization such as nonesterified fatty acids (NEFA; Bell, 1995). While lipid mobilization is a normal physiological response to help the cow adapt in these situations, excessive fat mobilization can be problematic. For instance, overproduction of ketones such as BHB occurs during times of high circulating NEFA concentrations when there is not a sufficient amount of Kreb's cycle intermediates to appropriately oxidize the acetyl coenzyme A produced by NEFA (Kuhla et al., 2016; Han van der Kolk et al., 2017). Additionally, increased concentrations of certain biomarkers, such as NEFA and BHB, have been linked to early-lactation disease and altered immune competence (Erdmann et al., 2018). Furthermore, the presence of aberrant nutrient metabolism, chronic inflammation, or oxidative stress can intensify the other factors that can cause metabolic stress, causing further problems (Trevisi et al., 2012; Esposito et al., 2014; Sordillo and Mavangira, 2014). For instance, increased plasma NEFA can lead to an increase in reactive oxygen species, which can exacerbate oxidative stress when present in excess. Oxidative stress can then contribute to dysregulated inflammatory responses and dyslipidemia (Sordillo et al., 2009). Cows entering the dry period may also experience dyslipidemia, chronic inflammation, or oxidative stress; however, assessments of these biomarkers have not been made during the physiological transition from late lactation to involution.

Cows undergoing the major physiological transition from lactating to nonlactating experience many stressors that may compromise their health and well-being. For instance, a cow entering the dry period is in her last trimester of pregnancy, when fetal growth is most rapid, milk production rapidly declines, and social stressors may occur due to moving to new pens with a new group of cows (Schirmann et al., 2011). Due to the similarities of potential stressors imposed on high-producing cows entering both the early dry period and early lactation,

Table 1. Diet of late-lactation and early dry cows for the study period

\begin{tabular}{lcc}
\hline Item (\% unless noted) & Late lactation & Far-off dry \\
\hline $\mathrm{NE}_{\mathrm{L}}{ }^{1}$ (Mcal/kg) & 1.5 & 1.15 \\
$\mathrm{CP}$ & 19 & 11 \\
$\mathrm{Fat}$ & 5.3 & 2.3 \\
$\mathrm{NFC}$ & 38 & 17 \\
Calcium & 0.75 & 0.51 \\
Phosphorus & 0.69 & 0.36 \\
Magnesium & 0.78 & 0.31 \\
Potassium & 1.4 & 2.5 \\
Sodium & 0.29 & 0.34 \\
Chloride & 0.53 & 0.99 \\
Sulfur & 0.3 & 0.18 \\
Selenium (mg/L) & 6.2 & 23 \\
Vitamin E (IU/animal) & 290 & 1,064 \\
\hline
\end{tabular}

${ }^{1}$ Estimated energy of lactation for an animal consuming $3 \times$ its requirement. it can be anticipated that the cows will experience some changes in biomarkers of nutrient metabolism, oxidative stress, and inflammation that collectively may contribute to metabolic stress. Understanding changes in biomarkers associated with metabolic stress will give valuable insight into how the early dry period may affect animal health and welfare. Therefore, the goal of this study was to document changes in biomarkers of nutrient metabolism, oxidative stress, and inflammation present during the early dry period of dairy cows.

\section{MATERIALS AND METHODS}

\section{Animals}

This study was approved by the Michigan State University Institutional Animal Care and Use Committee. Animals were enrolled $56 \mathrm{~d}$ before the expected calving date with owner consent. Blood samples were collected from 29 Holstein dairy cows (326 \pm 5 DIM; range: 299-390 DIM) from a commercial herd that was free from clinical disease with SCC $<250 \times 10^{3}$ cells/ $\mathrm{mL}$. Cows had an average milk production of $34 \mathrm{~kg} / \mathrm{d}$ (range: $17.8-52.3 \mathrm{~kg}$ of milk/d) in the previous lactation. Parity ranged from 1 to 5 , and cows had an average BCS of 3.0 at the time of dry-off (range: 2.6-4.0). Cows had ad libitum access to a TMR and water. At d -6 , cows were fed a late-lactation diet and switched to a far-off dry cow diet at d 0 (Table 1 ). Cows remained on the far-off dry cow diet for the remainder of the study. Before drying off, cows were milked 2 times/d and were treated with a standard intramammary dry cow antimicrobial therapy to protect against new intramammary infections. All cows were housed in a freestall barn that was cooled via fans and grouped according to stage of lactation. As cows were dried off, they were moved from a late-lactation pen to a dry cow pen with a new group of animals. Animals were sampled in 4 cohorts based on dry-off date. Group $1(\mathrm{n}=13)$, group $2(\mathrm{n}=9)$, and group $3(\mathrm{n}=5)$ were all sampled during the summer over a 6 -wk period, whereas group $4(\mathrm{n}=$ 2 ) was sampled in the fall.

\section{Sample Collection and Processing}

Samples were collected aseptically in the morning between 0800 and $1000 \mathrm{~h}$ from the coccygeal vein in evacuated tubes containing serum separator and EDTA. Six collection time points were chosen as d -6 , $0,+1,+2,+6$, and +12 relative to the dry-off date. Samples were immediately stored on ice throughout the collection and processing stages.

Serum was harvested after centrifugation at 1,449 $\times$ $g$ for $15 \mathrm{~min}$ at $4^{\circ} \mathrm{C}$ and aliquoted. A serum aliquot 
from each cow was sent to Michigan State University's Veterinary Diagnostic Laboratory (Lansing, MI), where commercially available assays were used to quantify calcium, NEFA [HR Series NEFA-HR(2), Wako Life Sciences, Mountain View, CA], BHB (Catachem Inc., Bridgeport, CT), albumin (Beckman Coulter Inc., Brea, $\mathrm{CA}$ ), and cortisol concentrations on each collection day. An autoanalyzer (Olympus AU 640e, Beckman Coulter Inc.) was used to visualize the colorimetric measurements, and appropriate controls were used for quality control. Additional aliquots of serum were flash frozen in liquid nitrogen and stored at $-80^{\circ} \mathrm{C}$ pending analysis within 1 mo of collection for oxidative stress indicators and acute phase proteins.

Whole-blood samples collected in EDTA evacuated tubes were kept refrigerated at $4^{\circ} \mathrm{C}$ immediately upon returning from the farm until blood leukocyte differential analysis could be performed. A 4-way leukocyte differential was performed to quantify total leukocyte, neutrophil, lymphocyte, eosinophil, and monocyte concentrations on collection day using an automated blood leukocyte differential test (QScout BLD, Advanced Animal Diagnostics, Morrisville, NC).

\section{Haptoglobin}

A commercially available photometric colorimetric assay (Phase haptoglobin assay kit, Tridelta Development LLC., Boonton, NJ) was used to determine haptoglobin concentrations in serum following the manufacturer's instructions. Absorbance was read at 600 to $630 \mathrm{~nm}$ on a Infinite 200 Pro plate reader (Tecan, Männedorf, Switzerland). The intra- and interassay coefficients of variation were 2.47 and $0.74 \%$, respectively.

\section{Oxidative Stress}

Commercial assays were used to quantify oxidative stress indices following the manufacturer's instructions. Reactive oxygen and nitrogen species (RONS) concentrations were quantified in serum using an OxiSelect in vitro reactive oxygen species/RNS assay kit (Cell BioLabs Inc., San Diego, CA). In brief, free radicals that exist in the sample will attach to a dichlorodihydrofluorescin DiOxyQ probe, converting dichlorodihydrofluorescin to a product that fluoresces (2',7'-dichlorodihydrofluorescein). Thus, fluorescence is proportional to the amount of RONS in the sample. All 96-well microtiter plates (Black Isoplate-96, PerkinElmer, Waltham, MA) were read using an Infinite 200 Pro plate reader (Tecan). Dichlorofluorescent dye fluorescence was determined at $480 \mathrm{~nm}$ of excitation and $530 \mathrm{~nm}$ of emission. A standard curve $(0-10,000 \mathrm{nM})$ was created to ensure fluorescence at various concen- trations. Background fluorescence was eliminated by subtracting blank values from sample values (Abuelo et al., 2013). Units were measured as relative fluorescence units (RFU) per microliter.

Antioxidant potential (AOP) concentrations were determined in serum using trolox (synthetic vitamin $\mathrm{E}$ analog) equivalents (TE) antioxidant capacity as previously described (Re et al., 1999). Antioxidant components interact in serum, and it is difficult to measure each antioxidant separately. As such, this method accounts for all antioxidants present in a sample, such as albumin, thiols, bilirubin, and superoxide dismutase. In short, a known amount of trolox standard concentration will result in a similar reduction of the radical 2,2'-azino-bis-3-ethylbenzothiazoline-6-sulfonic acid (Sigma-Aldrich, St. Louis, MO) based on the standard curve $(0-25 \mathrm{mg} / \mathrm{mL})$. Shifts in oxidative balance can result from an increase in RONS, a decrease in AOP, or changes in both parameters. Thus, an oxidant status index (OSi) was calculated as RONS/AOP to characterize shifts in oxidative balance (Abuelo et al., 2013).

Targeted analyses of plasma isoprostanes (IsoP), which are highly sensitive and specific products of lipid peroxidation associated with oxidative stress, were quantified using liquid chromatography-tandem MS. The specific isomers analyzed were $5,9 \alpha, 11 \alpha$-trihydroxy-

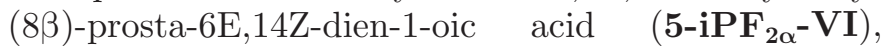
12-iso-5(R),6E,14Z-prostaglandin $\mathrm{F}_{2 \alpha} \quad\left(8,12\right.$-iso-iPF ${ }_{2 \alpha^{-}}$ VI), 8-iso-prostaglandin $\mathrm{E}_{2}$ (8-iso-PGE $\mathbf{F}_{2}$ ), 8-iso-15-keto-prostaglandin $\quad \mathrm{E}_{2}$ (8-iso-15-keto-PGE $\left.\mathbf{F}_{2}\right)$, 8-iso15(R)-prostaglandin $\mathrm{F}_{2 \alpha}\left[\mathbf{8}\right.$-iso-15(R)-PGF $\left.\mathbf{F}_{2 \alpha}\right]$, 8-isoprostaglandin $\mathrm{A}_{1}$ (8-iso-PGA $\mathbf{A}_{\mathbf{1}}$ ), 8-iso-prostaglandin $\mathrm{A}_{2}$ (8-iso-PGA $\mathbf{A}_{2}$ ), 15- $\mathrm{F}_{2 \mathrm{t}}$-Iso (formerly 8-iso-prostaglandin $\mathrm{F}_{2 \alpha}$ ), and 2,3-dinor-8-iso prostaglandin $\mathrm{F}_{2 \alpha}$ (2,3-dinor8-iso-PGF $\mathbf{F}_{2 \alpha}$ ). Samples were collected, extracted, and batch analyzed using methods published previously by Mavangira et al. (2016) with slight modification. Briefly, $1 \mathrm{~mL}$ of flash-frozen plasma was thawed on ice and mixed with an antioxidant-reducing agent and cyclooxygenase inhibitor mixture at $4 \mu \mathrm{L} / \mathrm{mL}$ to prevent degradation of preformed oxylipids and prevent ex vivo lipid peroxidation. The antioxidant-reducing agent mixture consisted of $50 \%$ methanol, $25 \%$ ethanol, and $25 \%$ water with $0.9 \mathrm{~m} M$ butylated hydroxytoluene, 0.54 $\mathrm{m} M$ EDTA, $3.2 \mathrm{~m} M$ tetraphenylporphyrin, and $5.6 \mathrm{~m} M$ indomethacin. Samples were combined with a $15-\mu \mathrm{L}$ mixture of deuterated internal standards containing $0.25 \mu M 5(\mathrm{~S})$-hydroxyeicosatetraenoic acid- $d_{8}, 0.25 \mu M$ $15(\mathrm{~S})$-hydroxyeicosatetraenoic acid- $d_{8}, 0.5 \mu M$ 8(9)-epoxyeicosatrienoic acid- $d_{11}, 0.5 \mu M$ prostaglandin $\mathrm{E}_{2}-d_{9}$, and $0.25 \mu M$ 8,9-dihydroxyeicosatrienoic acid- $d_{11}$. Afterward, methanol was added to yield a $60 \%$ methanol solution. Samples were vortexed for 2 min, incubated at room temperature for $15 \mathrm{~min}$, and centrifuged at 4,816 
$\times g$ for $20 \mathrm{~min}$ at $4^{\circ} \mathrm{C}$. Supernatant was diluted with HPLC water to yield a $20 \%$ methanol solution. Solid phase extraction was carried out using Phenomenox (Torrance, CA) Strata-X 33- $\mu \mathrm{m}$ polymeric reversedphase $200 \mathrm{mg} / 3 \mathrm{~mL}$ columns preconditioned with $3 \mathrm{~mL}$ of methanol followed by $3 \mathrm{~mL}$ of HPLC water. Supernatants were loaded into the columns and then washed with 20\% methanol and eluted with a 50:50 mixture of methanol and acetonitrile with $2 \%$ formic acid. Volatile solvents were dissolved using a Savant SpeedVac (ThermoFisher Scientific, Waltham, MA), and residues were reconstituted in methanol, mixed at a 2:1 ratio with HPLC water, and stored in chromatography vials at $-80^{\circ} \mathrm{C}$ until analysis. Quantification of IsoP was carried out on a Waters (Milford, MA) Xevo TQ-S tandem quadrupole mass spectrometer using multiple reaction monitoring. Chromatography separation was performed with a Waters Acquity UPLC BEH C18 column $(1.7 \mu \mathrm{m}, 2.1 \times 150 \mathrm{~mm})$ held at $50^{\circ} \mathrm{C}$ and autosampler held at $10^{\circ} \mathrm{C}$. Mobile phase bottle $\mathrm{A}$ was water containing $0.1 \%$ acetic acid, mobile phase bottle $\mathrm{B}$ was acetonitrile, and mobile phase bottle $\mathrm{C}$ was methanol; the flow rate was $0.3 \mathrm{~mL} / \mathrm{min}$. Liquid chromatography separation took $10 \mathrm{~min} /$ sample. Concentrations of IsoP were detected using electrospray ionization in negativeion mode. Cone voltages and collision voltages were optimized for each analyte using Waters QuanOptimize software, and data analysis was carried out with Waters TargetLynx software.

\section{Statistical Analyses}

Repeated-measures linear mixed effects models were constructed using the PROC MIXED procedure in SAS 9.4. (SAS Institute Inc., Cary, NC) to assess trends in concentrations of metabolic biomarkers over the study period. The biomarkers included calcium, NEFA, BHB, albumin, haptoglobin, cortisol, total leukocytes, neutrophils, lymphocytes, eosinophils, monocytes, RONS, $\mathrm{AOP}, \mathrm{OSi}$, and IsoP. Each biomarker was tested in a separate model that included the fixed effect of time point and a random intercept for cow, which accounted for the dependence between samples taken from the same cow. A spatial covariance residual matrix was used to account for unequal spacing between time points. Normality of residuals was visually assessed with quantile-quantile plots and histograms. Data that violated the normality assumption were transformed by either the $\log$ or square root function. Levene's test and graphs of predicted residuals were used to assess heteroscedasticity, which is when the variance of the residuals is unequal. Degrees of freedom were estimated using the Kenward-Roger approximation if heteroscedasticity was present. Differences in concentrations of biomarkers between different time points were tested using multiple group comparisons with a Bonferroni adjustment. Statistical significance was set at $P<0.05$.

\section{RESULTS}

Many of the biomarkers indicative of altered nutrient metabolism varied over the sampling period from $\mathrm{d}-6$ to $\mathrm{d}+12$. Table 2 depicts the mean and standard error for altered nutrient metabolism biomarkers over the sampling period. Calcium concentrations were higher at $\mathrm{d}+2($ mean $=2.58 \mathrm{mmol} / \mathrm{L})$ than the other time points $(P<0.01)$. Mean concentrations of NEFA were $0.15 \mathrm{mmol} / \mathrm{L}$ at $\mathrm{d}-6$ and reached highest mean concentrations of $0.59 \mathrm{mmol} / \mathrm{L}$ at $\mathrm{d}+1(P<0.1)$. After $\mathrm{d}+1$, NEFA concentrations began to decrease and approached those seen before dry-off by $\mathrm{d}+12$ (mean $=$ $0.18 \mathrm{mmol} / \mathrm{L}$ ). Lowest concentrations of BHB were 0.48 $\mathrm{mmol} / \mathrm{L}$ at $\mathrm{d} 0$, and highest concentrations were 0.72 $\mathrm{mmol} / \mathrm{L}$ at $\mathrm{d}+2(P<0.001)$.

Almost all indicators of inflammation changed over the sampling period, as shown in Table 3. The negative acute phase protein albumin generally remained consistent, but a decrease was noted at $\mathrm{d}+12$ with a mean concentration of $32.5 \mathrm{~g} / \mathrm{L}(P<0.01)$. Haptoglobin is a positive acute-phase protein that increased at $\mathrm{d}+12$ to a mean concentration of $0.32 \mathrm{~g} / \mathrm{L}(P<0.01)$. Similarly, cortisol concentrations peaked at $\mathrm{d}+1$ with a concentration of $13.8 \mathrm{mmol} / \mathrm{L}$. Cortisol concentrations were lower at $\mathrm{d}+6$ and +12 with concentrations of 4.91 and $3.68 \mathrm{mmol} / \mathrm{L}$, respectively, than $\mathrm{d}+1(P<0.01)$. Table 4 indicates changes in blood leukocytes over the

Table 2. Changes in biomarkers of nutrient metabolism during the dry-off period in 29 healthy Holstein cows

\begin{tabular}{|c|c|c|c|c|c|c|c|}
\hline \multirow[b]{2}{*}{ Biomarker (mmol/L) } & \multicolumn{6}{|c|}{ Day relative to dry-off } & \multirow[b]{2}{*}{$\mathrm{SE}$} \\
\hline & -6 & 0 & +1 & +2 & +6 & +12 & \\
\hline Calcium*** & $2.42^{\mathrm{bc}}$ & $2.36^{\mathrm{cd}}$ & $2.48^{\mathrm{b}}$ & $2.58^{\mathrm{a}}$ & $2.46^{\mathrm{b}}$ & $2.33^{\mathrm{d}}$ & 0.02 \\
\hline $\mathrm{NEFA}^{1, * * *}$ & $0.15^{\mathrm{c}}$ & $0.24^{\mathrm{bc}}$ & $0.59^{\mathrm{a}}$ & $0.33^{\mathrm{b}}$ & $0.22^{\mathrm{c}}$ & $0.18^{\mathrm{c}}$ & 0.03 \\
\hline $\mathrm{BHB}^{* * *}$ & $0.68^{\mathrm{ab}}$ & $0.48^{\mathrm{c}}$ & $0.67^{\mathrm{ab}}$ & $0.72^{\mathrm{a}}$ & $0.51^{\mathrm{c}}$ & $0.56^{\mathrm{bc}}$ & 0.03 \\
\hline
\end{tabular}


Table 3. Changes in inflammatory indicators during the dry-off period in 29 healthy Holstein cows

\begin{tabular}{|c|c|c|c|c|c|c|c|}
\hline \multirow[b]{2}{*}{ Biomarker } & \multicolumn{6}{|c|}{ Day relative to dry-off } & \multirow[b]{2}{*}{$\mathrm{SE}$} \\
\hline & -6 & 0 & +1 & +2 & +6 & +12 & \\
\hline$\overline{\text { Albumin } * * *(g / L)}$ & $35^{\mathrm{abc}}$ & $34.9^{\mathrm{bc}}$ & $35.6^{\mathrm{a}}$ & $35.2^{\mathrm{ab}}$ & $34.3^{\mathrm{c}}$ & $32.5^{\mathrm{d}}$ & 0.4 \\
\hline Haptoglobin ${ }^{1, * * *}(\mathrm{~g} / \mathrm{L})$ & $0.05^{\mathrm{b}}$ & $0.06^{\mathrm{b}}$ & $0.06^{\mathrm{b}}$ & $0.07^{\mathrm{b}}$ & $0.04^{\mathrm{b}}$ & $0.32^{\mathrm{a}}$ & 0.001 \\
\hline Cortisol $^{1, * * *}(\mathrm{mmol} / \mathrm{L})$ & $9.8^{\mathrm{ab}}$ & $7.0^{\mathrm{abc}}$ & $13.8^{\mathrm{a}}$ & $10.1^{\mathrm{ab}}$ & $4.9^{\mathrm{bc}}$ & $3.68^{\mathrm{c}}$ & 0.08 \\
\hline
\end{tabular}

sampling period. Lowest total leukocyte concentrations were reached at $\mathrm{d}+1$ and $+2\left(8.23\right.$ and $8.39 \times 10^{3}$ cells $/ \mu \mathrm{L}$, respectively). Neutrophil concentrations were lower at $\mathrm{d}+1\left(\right.$ mean $=3.88 \times 10^{3}$ cells $\left./ \mu \mathrm{L}\right)$ and $\mathrm{d}+2$ $\left(\right.$ mean $=3.94 \times 10^{3}$ cells $\left./ \mu \mathrm{L}\right)$ compared with $\mathrm{d}-6$ $\left(\right.$ mean $=4.79 \times 10^{3}$ cells $\left./ \mu \mathrm{L} ; P<0.01\right)$. The lowest concentrations of lymphocytes were 4.07 and $4.08 \times 10^{3}$ cells $/ \mu \mathrm{L}$ at $\mathrm{d}+2$ and +12 , respectively, which differed from $\mathrm{d}-6\left(\right.$ mean $=4.85 \times 10^{3}$ cells $\left./ \mu \mathrm{L} ; P<0.01\right)$. Eosinophil concentrations steadily increased from a mean concentration of $0.07 \times 10^{3}$ cells $/ \mu \mathrm{L}$ at $\mathrm{d}-6$ to $0.24 \times$ $10^{3}$ cells $/ \mu \mathrm{L}$ at $\mathrm{d}+12(P<0.01)$. Monocyte concentrations were higher at $\mathrm{d}-6$ and 0 (mean $=0.27$ and 0.25 $\times 10^{3}$ cells $/ \mu \mathrm{L}$, respectively) compared with the other sampling points except $\mathrm{d}+6$, which had a mean of 0.23 $\times 10^{3}$ cells $/ \mu \mathrm{L}(P<0.05)$.

All biomarkers of oxidant status varied over the sampling period. Table 5 represents changes in direct measures of oxidant status. Reactive oxygen and nitrogen species concentrations were lowest at $\mathrm{d}+2$ (mean $=12.0 \mathrm{RFU} / \mu \mathrm{L}$ ), which was lower than all other time points $(P<0.01)$ except $\mathrm{d}-6$. Concentrations of AOP were lower at $\mathrm{d}+2($ mean $=14.4 \mathrm{TE} / \mu \mathrm{L})$ and $\mathrm{d}+12$ $($ mean $=13.5 \mathrm{TE} / \mu \mathrm{L})$ compared with the other sampling points $(P<0.05$ and $<0.01$, respectively $)$. The OSi tended to increase from the previous time point at all sampling times except $d+2$. The lowest OSi was observed at $\mathrm{d}-6$ and $\mathrm{d}+2$ compared with the highest OSi at $\mathrm{d}+12(P<0.001)$. The different IsoP isomers measured in this study had varied responses through the sampling period. The isomers 8 -iso- $\mathrm{PGE}_{2}$ and 2,3-dinor-8-iso- $\mathrm{PGF}_{2 \alpha}$ were undetectable throughout the study. Concentrations of 8,12-iso-PGF ${ }_{2 \alpha}$-VI, 8-iso$15(\mathrm{R})-\mathrm{PGF}_{2 \alpha}$, and 8-iso-15-keto-PGE $\mathrm{PG}_{2}$ did not differ over the sampling period and are shown in Table 6 . In contrast, other IsoP did change over the sampling period. Concentrations of $5-\mathrm{iPF}_{2 \alpha}-\mathrm{VI}$ remained relatively stable from $\mathrm{d}-6$ to +6 but increased to the highest concentrations at $\mathrm{d}+2(P<0.01$; Figure 1$)$. Concentrations of $15-\mathrm{F}_{2 \mathrm{t}}$-Iso gradually increased following the abrupt cessation of lactation and reached highest concentrations of the study $(0.69 \mathrm{n} M)$ at $\mathrm{d}+2$ before returning to baseline amounts $(0.2 \mathrm{n} M)$ by $\mathrm{d}+6$ (Figure 2). Although the ANOVA detected differences for $15-\mathrm{F}_{2 \mathrm{t}}$-Iso $(P<0.01)$, no pairwise comparisons differed between sampling points after Bonferroni adjustment. The dehydration IsoP products of 8-iso- $\mathrm{PGE}_{2}, 8$-iso$\mathrm{PGA}_{1}$, and 8-iso-PGA 2 both differed over the sampling period (Figure 3). Concentrations of 8-iso- $\mathrm{PGA}_{1}$ were higher at $\mathrm{d}+12(0.59 \mathrm{n} M)$ than all other sampling points $(P<0.01)$, whereas 8 -iso- $\mathrm{PGA}_{2}$ was lower at $\mathrm{d}+12(1.51 \mathrm{n} M)$ compared with $\mathrm{d}+2(3.24 \mathrm{n} M ; P<$ $0.05)$.

\section{DISCUSSION}

This study highlighted that biomarkers of nutrient metabolism, inflammation, and oxidative stress indeed changed throughout the transition into the early dry period, particularly in the first $2 \mathrm{~d}$ after abrupt milking cessation. Altered nutrient metabolism is related to many metabolic and inflammatory conditions in

Table 4. Changes in blood leukocyte counts during the dry-off period in 29 healthy Holstein cows

\begin{tabular}{lccccccc}
\hline & \multicolumn{5}{c}{ Day relative to dry-off } & \\
\cline { 2 - 6 } Biomarker $\left(10^{3} / \mu \mathrm{L}\right)$ & -6 & 0 & +1 & +2 & +6 & +12 & SE \\
\hline Total leukocytes*** & $10.0^{\mathrm{a}}$ & $9.46^{\mathrm{ab}}$ & $8.29^{\mathrm{c}}$ & $8.39^{\mathrm{c}}$ & $9.27^{\mathrm{ac}}$ & $8.69^{\mathrm{bc}}$ & 0.53 \\
Neutrophils*** & $4.79^{\mathrm{a}}$ & $4.43^{\mathrm{ac}}$ & $3.88^{\mathrm{b}}$ & $3.94^{\mathrm{bc}}$ & $4.48^{\mathrm{abc}}$ & $4.13^{\mathrm{abc}}$ & 0.23 \\
Lymphocytes*** & $4.85^{\mathrm{a}}$ & $4.68^{\mathrm{ab}}$ & $4.13^{\mathrm{bc}}$ & $4.07^{\mathrm{c}}$ & $4.37^{\mathrm{abc}}$ & $4.08^{\mathrm{c}}$ & 0.34 \\
Eosinophils*** & $0.07^{\mathrm{bc}}$ & $0.06^{\mathrm{c}}$ & $0.07^{\mathrm{bc}}$ & $0.14^{\mathrm{abc}}$ & $0.17^{\mathrm{ab}}$ & $0.24^{\mathrm{a}}$ & 0.03 \\
Monocytes*** & $0.27^{\mathrm{a}}$ & $0.25^{\mathrm{ab}}$ & $0.17^{\mathrm{c}}$ & $0.19^{\mathrm{bc}}$ & $0.23^{\mathrm{abc}}$ & $0.19^{\mathrm{bc}}$ & 0.02 \\
\hline
\end{tabular}

${ }^{a-c}$ Means within a row with different superscripts differ $(P<0.05)$.

***ANOVA $P$-value $<0.001$. 
Table 5. Changes in biomarkers of oxidant status during the dry-off period in 29 healthy Holstein cows

\begin{tabular}{|c|c|c|c|c|c|c|c|}
\hline Biomarker $^{1}$ & \multicolumn{6}{|c|}{ Day relative to dry-off } & $\mathrm{SE}$ \\
\hline Reactive oxygen and nitrogen species*** $(\mathrm{RFU} / \mu \mathrm{L})$ & $14.8^{\mathrm{bc}}$ & $19.4^{\mathrm{a}}$ & $19.6^{\mathrm{a}}$ & $12.0^{\mathrm{c}}$ & $17.2^{\mathrm{ab}}$ & $17.5^{\mathrm{ab}}$ & 2.1 \\
\hline Oxidant status index ${ }^{* * *}$ (RFU/TE) & $1.02^{\mathrm{b}}$ & $1.12^{\mathrm{ab}}$ & $1.16^{\mathrm{ab}}$ & $0.89^{\mathrm{b}}$ & $1.09^{\mathrm{ab}}$ & $1.33^{\mathrm{a}}$ & 0.18 \\
\hline
\end{tabular}

${ }^{\mathrm{a}-\mathrm{c}}$ Means within a row with different superscripts differ $(P<0.05)$.

${ }^{1} \mathrm{RFU}=$ relative fluorescence units; $\mathrm{TE}=$ trolox equivalents.

***ANOVA $P$-value $<0.001$.

periparturient cows (Sordillo and Mavangira, 2014). In the present study, mean calcium concentrations varied between many of the sampling points and approached the upper reference limit of $2.6 \mathrm{mmol} / \mathrm{L}$ during the first several days after dry-off. In the past, a proposed treatment for hypocalcemia was to increase pressure in the mammary gland via insufflation, which increased blood calcium concentrations (Marshak, 1956). This treatment was successful for 2 potential reasons: calcium demands decreased after milking cessation, and milk accumulation in the mammary gland led to weakening of tight junctions between mammary epithelial cells, resulting in increased paracellular transport of calcium into the blood (Aslam and Tucker, 1998). Similarly, cows in early involution have decreased calcium demands and increased intramammary pressure when milking is ceased, which may explain the increased concentrations noted in the present study.

Elevated concentrations of NEFA and BHB are indicators of negative energy balance (Abdelli et al., 2017). The peak NEFA concentration noted in this study occurred during the first day of involution. Early involution was previously shown to involve inflammatory processes that may cause an increase in NEFA concentrations (Kushibiki et al., 2003). Increased NEFA concentrations also occur in a fasting state, causing some lipid mobilization (Sordillo and Mavangira, 2014). The increase in NEFA concentration observed in this study may also be due to reduced feed intake as a result of displacement of cows from the feed bunk when they were mixed with a new group of cows in the first few days of dry-off. A previous study suggests that herd NEFA concentrations $>0.4 \mathrm{mEq} / \mathrm{L}$ prepartum or $>0.7$ $\mathrm{mEq} / \mathrm{L}$ postpartum are indicative of increased risk of developing diseases and production losses such as displaced abomasum (Ospina et al., 2010). Although NEFA concentrations noted in this study approached this level at 1 sampling point, the concentrations were lower than the accepted prepartum disease risk concentrations of $0.4 \mathrm{mEq} / \mathrm{L}$ at all other sampling points (Ospina et al., 2010). To date, there is no information on what the NEFA concentrations would be around the time of dry-off that would indicate increased risk of early-lactation disease incidence. The ability to use alerted NEFA concentrations during the early dry period as a potential tool for predicting disease risk in the ensuing lactation may allow for sufficient time to adjust nutritional management practices to optimize health in periparturient cows.

Similar to NEFA, BHB concentrations tend to increase as cows approach calving and as glucose concentrations decrease (Farahani et al., 2017). In the present study, BHB concentrations decreased as the dry-off date approached. The differences can be attributed to cows being in an improved energy balance as lactation ends and therefore having more carbohydrate available to fully oxidize NEFA as opposed to shifting to ketone synthesis via incomplete oxidation. Previous studies suggest that a herd prepartum concentration for BHB of at least $12 \mathrm{mg} / \mathrm{dL}$ is associated with increased risk of

Table 6. Changes in select indicators of arachidonic acid peroxidation during the dry-off period in 10 healthy cows

\begin{tabular}{|c|c|c|c|c|c|c|c|}
\hline \multirow[b]{2}{*}{ Biomarker (nM) } & \multicolumn{6}{|c|}{ Day relative to dry-off } & \multirow[b]{2}{*}{$\mathrm{SE}$} \\
\hline & -6 & 0 & +1 & +2 & +6 & +12 & \\
\hline 8,12 -iso-iPF ${ }_{2 \alpha}-\mathrm{VI}^{1}$ & 0.12 & 0.19 & 0.14 & 0.14 & 0.1 & 0.14 & 0.004 \\
\hline 8-iso-15(R)-PGF ${ }_{2 \alpha}{ }^{2}$ & 0.12 & 0.12 & 0.13 & 0.1 & 0.02 & Undetectable & 0.003 \\
\hline 8-iso-15-keto- $\mathrm{PGE}_{2}{ }^{3}$ & 0.24 & 0.25 & 0.3 & 0.27 & 0.15 & 0.13 & 0.004 \\
\hline
\end{tabular}




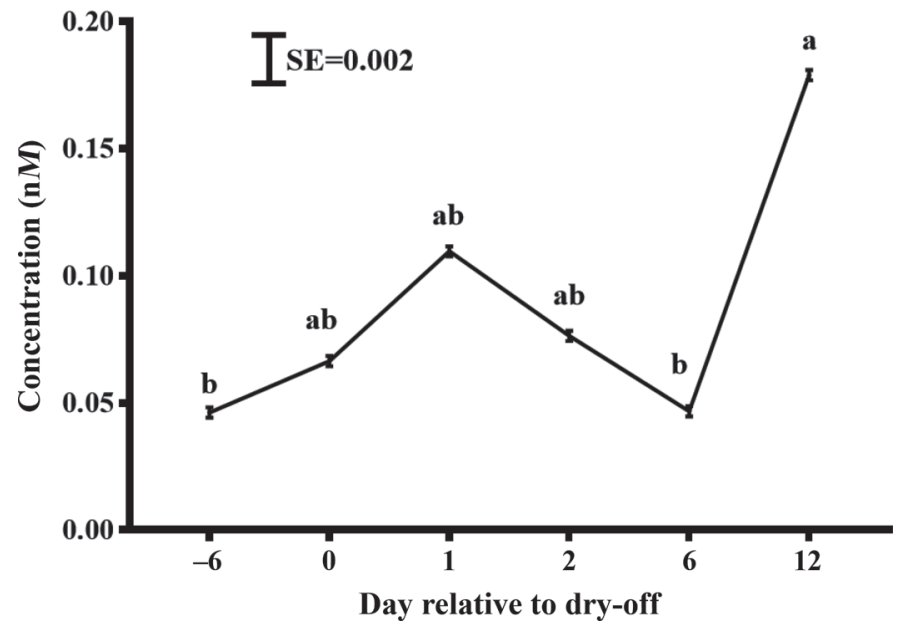

Figure 1. Changes in plasma $5,9 \alpha, 11 \alpha$-trihydroxy-(8$\beta)$-prosta$6 \mathrm{E}, 14 \mathrm{Z}$-dien-1-oic acid $\left(5-\mathrm{iPF}_{2 \alpha}-\mathrm{VI}\right)$ concentrations from baseline $(\mathrm{d}$ $-6)$ to $d+12$ after dry-off in healthy cows $(n=10)$. Means with different letters $(\mathrm{a}, \mathrm{b})$ are different $(P<0.05)$. Data are presented as means \pm SE. Error bars are partially obscured by data points due to small SE.

early-lactation diseases (Ospina et al., 2010). None of the samples collected in our study reached the $12 \mathrm{mg} /$ $\mathrm{dL}$ of BHB threshold that was associated with increased risk for certain postcalving diseases and production losses seen in periparturient cows. It is important to note, however, that sampling occurred immediately after the cows were fed, which could have an effect on the BHB concentrations due to butyrate conversion to BHB by rumen epithelia cells (Remling et al., 2014). Therefore, the variations in BHB concentrations noted in the present study may correspond to physiological

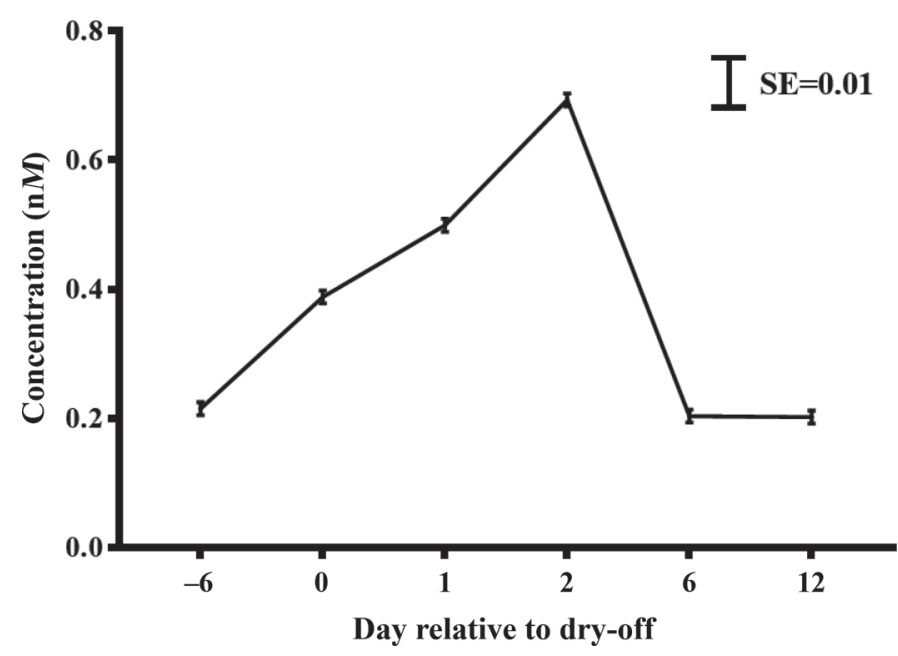

Figure 2. Changes in $15-\mathrm{F}_{2 \mathrm{t}}$-Iso from baseline $(\mathrm{d}-6)$ to $\mathrm{d}+12$ after the cessation of lactation in healthy cows $(\mathrm{n}=10)$. Data are presented as means \pm SE. Error bars are partially obscured by data points due to small SE. changes associated with feeding. Moreover, no studies have been conducted to date that would suggest that increases in either NEFA or BHB concentrations around the time of dry-off would have any effect on disease incidence in periparturient cows. There is evidence, however, that NEFA concentrations representative of those found in healthy cows can still affect immune competence. Lacetera et al. (2004) found that NEFA concentrations as low as $0.25 \mathrm{mmol} / \mathrm{L}$ could decrease IgM secretion and that concentrations as low as 0.125 $\mathrm{mmol} / \mathrm{L}$ could suppress interferon gamma secretion in peripheral blood mononuclear cells. Thus, it can be reasoned that cows at dry-off may also be subject to these immunosuppressive effects because the NEFA concentrations noted in the present study were consistently higher than $0.125 \mathrm{mmol} / \mathrm{L}$. Due to the complex interactions between altered nutrient metabolism and inflammatory indices that contribute to metabolic stress and disease occurrence (Trevisi et al., 2012), it would be beneficial to investigate whether there are any correlations between NEFA or BHB concentrations at dry-off and periparturient disease risk.

Dysfunctional inflammation contributes to metabolic disturbances of dairy cows (Sordillo et al., 2009; Esposito et al., 2014). Certain blood proteins, known as the acute phase proteins, are considered to be highly sensitive indicators of inflammation because serum concentrations change $>25 \%$ during an inflammatory response (Eckersall and Bell, 2010). Albumin is considered to be a negative acute phase protein associated

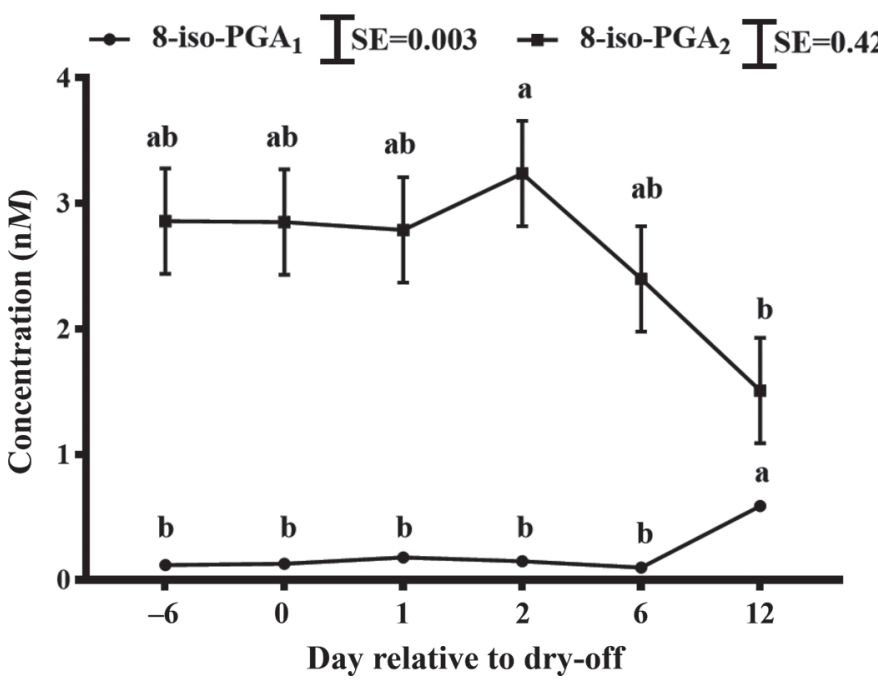

Figure 3. Changes in dehydration products of 8-iso-prostaglandin $\mathrm{E}_{2}$ (8-iso- $\mathrm{PGE}_{2}$ ) throughout the sampling period $(\mathrm{n}=10)$. Mean concentrations with different letters $(\mathrm{a}, \mathrm{b})$ are different $(P<0.05)$. Data are presented as means \pm SE. Error bars for 8-iso-prostaglandin $\mathrm{A}_{1}$ (8-iso- $\left.\mathrm{PGA}_{1}\right)$ are obscured by data points due to small SE. 8-iso$\mathrm{PGA}_{2}=8$-iso-prostaglandin $\mathrm{A}_{2}$. 
with the resolution of inflammation (Zou et al., 2017). Brscic et al. (2015) reported albumin concentrations of $36.3 \mathrm{~g} / \mathrm{L}$ for healthy dry cows, which is similar to the concentrations noted in this study. Serum haptoglobin has been stated as a valid biomarker that can distinguish diseased animals from healthy animals (Eckersall and Bell, 2010). Additionally, it has been reported that healthy cattle have serum haptoglobin concentrations $<20 \mathrm{mg} / \mathrm{L}$ (Eckersall and Bell, 2010). The mean concentrations of haptoglobin in this study were consistently higher than $20 \mathrm{mg} / \mathrm{L}$. In contrast to the cows in the Eckersall and Bell (2010) study that were not undergoing any known inflammatory processes; however, mammary gland involution involves inflammation as the tissue remodels and may explain the higher concentrations during the present study. The effect of increased concentrations of haptoglobin during the transition into the early dry period on subsequent health and well-being of the cow is still unknown, although an argument could be made that the presence of haptoglobin in the mammary gland during this time would be beneficial. Arslan et al. (2013) demonstrated that haptoglobin was important for appropriate matrix remodeling after myocardial infarction in mice, and dairy cows in early involution also experience matrix remodeling of the mammary gland.

Cortisol is a hormone paramount to daily functions and the stress response in cows (Locatelli et al., 1989; Hannibal and Bishop, 2014). Past work has indicated that cows regrouped into a high-density stocked pen have an increased cortisol response when stimulated with adrenocorticotropic hormone (Friend et al., 1977). The cows in our study were regrouped into a pen stocked to full capacity, which may explain the increased cortisol concentrations noted after dry-off. Additionally, past studies have shown that NEFA concentrations increase with increased cortisol concentrations (Locatelli et al., 1989). Therefore, a peak of NEFA concentrations at $d+1$ in this study may be related in part to the peak of cortisol concentrations observed at the same time. Under normal conditions in the periparturient cow, plasma cortisol concentrations begin increasing a few days before parturition until the calf is born. Baseline levels of cortisol are then reached within $24 \mathrm{~h}$ of calving (Hydbring et al., 1999). The differences noted between the animals in this study and periparturient cows can be attributed to the time at which stress occurs in the respective animals. Stress associated with labor can cause the increased cortisol concentrations of the periparturient cow (Hydbring et al., 1999), whereas animals entering the dry period experience stressors such as changing their social group at dry-off that can cause increased cortisol concentrations until the herd dynamics are established.
In general, total blood leukocytes, neutrophils, and lymphocytes followed similar patterns of changes throughout the study. It is well documented that leukocytes increase in the bovine mammary gland during acute involution (Sordillo and Nickerson, 1988). Therefore, the decrease of immune cells immediately following dry-off can be attributed to cells migrating from blood and into tissue (Atabai et al., 2007). Interestingly, eosinophils tended to steadily increase throughout the study. Typically associated with allergies and parasites, eosinophils have been shown to exist in healthy tissues, although their role is unclear (Gouon-Evans et al., 2000). For instance, Gouon-Evans et al. (2000) proposed that eosinophils are important for postnatal ductal branching of the mammary gland in mice. However, it is still unknown what role, if any, eosinophils may play in the involuting bovine mammary gland. Additionally, an autoallergy to the milk protein casein has been described in dairy cattle and develops within hours of dry-off (Peek and Divers, 2008). Therefore, the increased eosinophil concentrations may represent a subclinical hypersensitivity to the milk retained in the udder upon cessation of lactation. Alternatively, the combination of increased eosinophil and haptoglobin concentrations with decreased concentrations of albumin at $d+12$ could be indicative of an inflammatory response. Inflammation plays a pertinent role in metabolic stress in early-lactation cows (Sordillo and Mavangira, 2014); therefore, future studies should investigate how these changes may affect the health and well-being of cows during dry-off.

Oxidative stress occurs when there is an imbalance between RONS and antioxidant defenses and is a common disorder during periods of increased metabolic demands (Sordillo and Aitken, 2009; Abuelo et al., 2013). In accordance with the concept that antioxidants are produced in an attempt to minimize the damage induced by RONS (Sordillo and Aitken, 2009; Saeed-Zidane et al., 2017), concentrations of AOP generally followed the same pattern as RONS in the present study. However, OSi was highest at $d+12$ compared with all other sampling points, suggesting that this time point was when antioxidant defenses were lowest relative to RONS exposure. In an attempt to maintain antioxidant defense against increasing RONS, it is common to add antioxidant supplements to periparturient cow diets (Abuelo et al., 2013). However, it is unknown whether this practice would benefit cows entering the dry period and should be the focus of future investigations. Evaluating OSi, the ratio between RONS and AOP, has been indicated to provide a more accurate depiction of cow oxidant status compared with evaluating RONS or AOP concentrations alone (Abuelo et al., 2013). In our study, the OSi remained around $1 \mathrm{RFU} / \mathrm{TE}$, which 
suggests a balanced redox status for the animals. Based on this measurement alone, one might assume that the cows were unlikely to experience oxidative stress because changes in RONS appeared to be matched by changes in AOP. However, it is also important to consider macromolecule damage that can occur due to free radical production before making this conclusion.

Although oxidative status changed during the sampling period, direct measures of macromolecule damage, such as quantification of IsoP concentrations, must be assessed to determine potential harmful effects on host tissues (Sordillo, 2018). Isoprostanes are prostaglandin-like compounds that are produced by oxidation of PUFA such as arachidonic acid through interactions with free radicals such as RONS (Lawson et al., 1999). Measures of elevated $15-\mathrm{F}_{2 \mathrm{t}}$-Iso concentrations in particular are a valid biomarker of lipid peroxidation damage during severe oxidative stress in both humans and dairy cattle (Mavangira et al., 2016; Mavangira and Sordillo, 2018; Sordillo, 2018). The higher concentration of plasma $15-\mathrm{F}_{2 \mathrm{t}}$-Iso observed at $\mathrm{d}+2$ in this study may be a consequence of the gradual increase in RONS exposure leading up to this sampling time point. Indeed, the RONS at $d+1$ was higher compared with baseline measures observed before the abrupt cessation of lactation. Although oxidative stress is known to adversely affect the immune and inflammatory responses of dairy cows (Sordillo and Aitken, 2009), the consequence that elevated $15-\mathrm{F}_{2 \mathrm{t}}$-Iso concentrations may have on important host defenses during the early dry period has yet to be determined. Furthermore, it is still unknown whether there is significance to having differential IsoP isomer production throughout the early dry period. In our study, for instance, 8-iso$\mathrm{PGA}_{1}$ isomer increased at $\mathrm{d}+12$, whereas 8 -iso- $\mathrm{PGA}_{2}$ was decreased at this time (Figure 2). Although it is known that $\mathrm{E}_{2^{-}}$and $\mathrm{D}_{2}$-IsoP will preferentially be produced over $\mathrm{F}_{2}$-IsoP when reducing agents such as $\alpha$-tocopherol are depleted (Milne et al., 2011), there is still a paucity of knowledge regarding why certain isomers of related IsoP do not always get produced to the same magnitude at any given time. For instance, perhaps 8-iso- $\mathrm{PGA}_{1}$ is a proinflammatory IsoP and 8-iso-PGA $\mathrm{P}_{2}$ may be anti-inflammatory, and thus they would have opposite responses at the same time point. Therefore, further studies into the biological activities of IsoP may provide answers to these questions.

\section{CONCLUSIONS}

This study evaluated for the first time key biomarkers of altered nutrient metabolism, inflammation, and oxidative stress during the transition from late lactation and into the early dry period. Although many of the biomarkers changed during the initial stages of involution, the changes were not always equivalent with respect to magnitude and duration to those seen during the periparturient period. The data obtained from this study provide insight into alterations of nutrient metabolism, inflammation, and oxidative stress biomarkers during the major transition from a lactating state to a nonlactating state. However, it remains unknown whether the magnitude of these changes merely represents a physiological response, whether they are negatively affecting cow health, or whether there is a threshold at which these biomarkers would predict disease. Therefore, future studies are necessary to elucidate specific causes and potential effects of these changes on the health of cows throughout the dry period and into early lactation.

\section{ACKNOWLEDGMENTS}

This study was funded in part by support from the Agriculture and Food Research Initiative Competitive Grants Program (2014-68004-21972 and 2017-6701526676) from the USDA National Institute of Food and Agriculture (Washington, DC), an endowment from the Matilda R. Wilson Fund (Detroit, MI), and the Michigan Alliance for Animal Agriculture (East Lansing). We thank Advanced Animal Diagnostics (Morrisville, NC) for the kind gift of the automated blood leukocyte differential test, QScout BLD. We also thank the Michigan State University Mass Spectrometry and Metabolomics Core (East Lansing) for their assistance in liquid chromatography analysis.

\section{REFERENCES}

Abdelli, A., D. Raboisson, R. Kaidi, B. Ibrahim, A. Kalem, and M. Iguer-Ouada. 2017. Elevated non-esterified fatty acid and beta-hydroxybutyrate in transition dairy cows and their association with reproductive performance and disorders: A meta-analysis. Theriogenology 93:99-104. https://doi.org/10.1016/j.theriogenology.2017 .01 .030 .

Abuelo, A., J. Hernández, J. L. Benedito, and C. Castillo. 2013. Oxidative stress index (OSi) as a new tool to assess redox status in dairy cattle during the transition period. Animal 7:1374-1378. https://doi.org/10.1017/S1751731113000396.

Arslan, F., M. B. Smeets, B. Buttari, E. Profumo, R. Rigano, L. Akeroyd, E. Kara, L. Timmers, J. P. Sluijter, B. van Middelaar, K. den Ouden, G. Pasterkamp, S. K. Lim, and D. P. de Kleijn. 2013. Lack of haptoglobin results in unbalanced VEGFo/angiopoietin-1 expression, intramural hemorrhage and impaired wound healing after myocardial infarction. J. Mol. Cell. Cardiol. 56:116-128.

Aslam, M., and W. B. Tucker. 1998. Influence of intramammary infusion of calcium on the calcium status of periparturient lactating dairy cows. J. Dairy Sci. 81:1883-1888. https://doi.org/10.3168/ jds.S0022-0302(98)75759-5.

Atabai, K., D. Sheppard, and Z. Werb. 2007. Roles of the innate immune system in mammary gland remodeling during involution. J. Mammary Gland Biol. Neoplasia 12:37-45. https://doi.org/10 .1007/s10911-007-9036-6. 
Bell, A. W. 1995. Regulation of organic nutrient metabolism during transition from late pregnancy to early lactation. J. Anim. Sci. 73:2804-2819.

Brscic, M., G. Cozzi, I. Lora, A. L. Stefani, B. Contiero, L. Ravarotto, and F. Gottardo. 2015. Short communication: Reference limits for blood analytes in Holstein late-pregnant heifers and dry cows: Effects of parity, days relative to calving, and season. J. Dairy Sci. 98:7886-7892.

Eckersall, P. D., and R. Bell. 2010. Acute phase proteins: Biomarkers of infection and inflammation in veterinary medicine. Vet. J. 185:23-27. https://doi.org/10.1016/j.tvjl.2010.04.009.

Erdmann, S., E. Mohr, M. Derno, A. Tuchscherer, C. Schäff, S. Börner, U. Kautzsch, B. Kuhla, H. M. Hammon, and M. Röntgen 2018. Indices of heart rate variability as potential early markers of metabolic stress and compromised regulatory capacity in dried-off high-yielding dairy cows. Animal 12:1451-1461. https://doi.org/10 $.1017 /$ S1751731117002725.

Esposito, G., P. C. Irons, E. C. Webb, and A. Chapwanya. 2014. Interactions between negative energy balance, metabolic diseases, uterine health and immune response in transition dairy cows. Anim. Reprod. Sci. 144:60-71. https://doi.org/10.1016/j.anireprosci.2013 .11 .007 .

Farahani, T. A., H. Amanlou, and M. Kazemi-Bonchenari. 2017. Effects of shortening the close-up period length coupled with increased supply of metabolizable protein on performance and metabolic status of multiparous Holstein cows. J. Dairy Sci. 100:61996217. https://doi.org/10.3168/jds.2016-12263.

Friend, T. H., C. E. Polan, F. C. Gwazdauskas, and C. W. Heald. 1977. Adrenal glucocorticoid response to exogenous adrenocorticotropin mediated by density and social disruption in lactating cows. J. Dairy Sci. 60:1958-1963.

Gouon-Evans, V., M. E. Rothenberg, and J. W. Pollard. 2000. Postnatal mammary gland development requires macrophages and eosinophils. Development 127:2269-2282.

Han van der Kolk, J. H., J. J. Gross, V. Gerber, and R. M. Bruckmaier. 2017. Disturbed bovine mitochondrial lipid metabolism: A review. Vet. Q. 37:262-273. https://doi.org/10.1080/01652176 .2017 .1354561 .

Hannibal, K. E., and M. D. Bishop. 2014. Chronic stress, cortisol dysfunction, and pain: A psychoneuroendocrine rationale for stress management in pain rehabilitation. Phys. Ther. 94:1816-1825. https://doi.org/10.2522/ptj.20130597.

Hydbring, E., A. Madej, E. MacDonald, G. Drugge-Boholm, B. Berglund, and K. Olsson. 1999. Hormonal changes during parturition in heifers and goats are related to the phases and severity of labour. J. Endocrinol. 160:75-85.

Kuhla, B., C. C. Metges, and H. M. Hammon. 2016. Endogenous and dietary lipids influencing feed intake and energy metabolism of periparturient dairy cows. Domest. Anim. Endocrinol. 56(Suppl.):S2S10. https://doi.org/10.1016/j.domaniend.2015.12.002.

Kushibiki, S., K. Hodate, H. Shingu, Y. Obara, E. Touno, M. Shinoda, and Y. Yokomizo. 2003. Metabolic and lactational responses during recombinatnt bovine tumor necrosis factor- $\alpha$ treatment in lactating cows. J. Dairy Sci. 86:819-827. https://doi.org/10.3168/ jds.S0022-0302(03)73664-9.

Lacetera, N., D. Scalia, O. Franci, U. Bernabucci, B. Ronchi, and A. Nardone. 2004. Short communication: Effects of nonesterified fatty acids on lymphocyte function in dairy heifers. J. Dairy Sci. 87:1012-1014.

Lawson, J. A., J. Rokach, and G. A. FitzGerald. 1999. Isoprostanes: Formation, analysis and use as indices of lipid peroxidation in vivo. J. Biol. Chem. 274:24441-24444. https://doi.org/10.1074/jbc.274 .35 .24441 .

Locatelli, A., P. Sartorelli, F. Agnes, G. P. Bondiolotti, and G. B. Picotti. 1989. Adrenal response in the calf to repeated simulated transport. Br. Vet. J. 145:517-522. https://doi.org/10.1016/0007 $-1935(89) 90112-7$.

Marshak, R. R. 1956. Studies on parturient paresis in dairy cows with particular reference to udder insufflation. J. Am. Vet. Med. Assoc. 128:423-431.
Mavangira, V., M. J. Mangual, J. C. Gandy, and L. M. Sordillo. 2016. $15-\mathrm{F}_{2 \mathrm{t}}$-isoprostane concentrations and oxidant status in lactating dairy cattle with acute coliform mastitis. J. Vet. Intern. Med. 30:339-347.

Mavangira, V., and L. M. Sordillo. 2018. Role of lipid mediators in the regulation of oxidative stress and inflammatory responses in dairy cattle. Res. Vet. Sci. 116:4-14.

Mbata, O., N. F. Abo El-Magd, and A. B. El-Remessy. 2017. Obesity, metabolic syndrome and diabetic retinopathy: Beyond hyperglycemia. World J. Diabetes 8:317-329. https://doi.org/10.4239/wjd v8.i7.317.

Milne, G. L., H. Yin, K. D. Hardy, S. S. Davies, and L. J. Roberts 2nd.. 2011. Isoprostane generation and function. Chem. Rev. 111:5973-5996. https://doi.org/10.1021/cr200160h.

Ospina, P. A., D. V. Nydam, T. Stokol, and T. R. Overton. 2010 Association between the proportion of sampled transition cows with increased nonesterified fatty acids and beta-hydroxybutyrate and disease incidence, pregnancy rate, and milk production at the herd level. J. Dairy Sci. 93:3595-3601. https://doi.org/10.3168/ jds.2010-3074.

Peek, S., and T. J. Divers. 2008. Milk allergy in diseases of the teats and udder. Page 390 in Rebuhn's Diseases of Dairy Cattle. 2nd ed. Saunders Elsevier, St. Louis, MO.

Re, R., N. Pellegrini, A. Proteggente, A. Pannala, M. Yang, and C. Rice-Evans. 1999. Antioxidant activity applying an improved ABTS radical cation decolorization assay. Free Radic. Biol. Med. 26:1231-1237. https://doi.org/10.1016/S0891-5849(98)00315-3.

Remling, N., S. Riede, P. Lebzien, U. Meyer, M. Höltershinken, S. Kersten, G. Breves, G. Flachowsky, and S. Dänicke. 2014. Effects of fumaric acid on rumen fermentation, milk composition and metabolic parameters in lactating cows. J. Anim. Physiol. Anim. Nutr. (Berl.) 98:968-981. https://doi.org/10.1111/jpn.12152.

Saeed-Zidane, M., L. Linden, D. Salilew-Wondim, E. Held, C. Neuhoff, E. Tholen, M. Hoelker, K. Schellander, and D. Tesfaye. 2017. Cellular and exosome mediated molecular defense mechanism in bovine granulosa cells exposed to oxidative stress. PLoS One 12:0187569. https://doi.org/10.1371/journal.pone.0187569.

Schirmann, K., N. Chapinal, D. M. Weary, W. Heuwieser, and M. A. von Keyserlingk. 2011. Short-term effects of regrouping on behavior of prepartum dairy cows. J. Dairy Sci. 94:2312-2319. https:// doi.org/10.3168/jds.2010-3639.

Sordillo, L. M. 2018. Oxylipids and the regulation of bovine mammary inflammatory responses. J. Dairy Sci. 101:5629-5641.

Sordillo, L. M., and S. L. Aitken. 2009. Impact of oxidative stress on the health and immune function of dairy cattle. Vet. Immunol. Immunopathol. 128:104-109.

Sordillo, L. M., G. A. Contreras, and S. L. Aitken. 2009. Metabolic factors affecting the inflammatory response of periparturient dairy cows. Anim. Health Res. Rev. 10:53-63.

Sordillo, L. M., and V. Mavangira. 2014. The nexus between nutrient metabolism, oxidative stress and inflammation in transition cows. Anim. Prod. Sci. 54:1204-1214.

Sordillo, L. M., and S. C. Nickerson. 1988. Morphologic changes in the bovine mammary gland during involution and lactogenesis. Am. J. Vet. Res. 49:1112-1120.

Trevisi, E., M. Amadori, S. Cogrossi, E. Razzuoli, and G. Bertoni. 2012. Metabolic stress and inflammatory response in high-yielding, periparturient dairy cows. Res. Vet. Sci. 93:695-704.

Zobel, G., D. M. Weary, K. E. Leslie, and M. A. von Keyserlingk. 2015 Invited review: Cessation of lactation: Effects on animal welfare. J. Dairy Sci. 98:8263-8277. https://doi.org/10.3168/jds.2015-9617.

Zou, Y., Y. Wang, Y. Deng, Z. Cao, S. Li, and J. Wang. 2017. Effects of feeding untreated, pasteurized and acidified waste milk and bunk tank milk on the performance, serum metabolic profiles, immunity, and intestinal development in Holstein calves. J. Anim. Sci. Biotechnol. 8:53. https://doi.org/10.1186/s40104-017-0182-4. 